\title{
DETERMINATION OF TOOTH LENGTH VARIATION OF MAXILLARY CANINE - AN ANALYTICAL STUDY
}

\author{
DeependraNaulakha, ManishAgrawal, NootanNaulakha
}

\begin{abstract}
:
Aim:The Aim of this study was to assess the variation in anatomical tooth length of maxillary canine, irrespective of sex, in patient's presenting at NMCTH, Biratnagar,Nepal.

Methodology: A total of 30 Endodontically treated maxillary canine were included in this study. Preoperative radiographs were taken initially for finding the canal length. Radiographic interpretation (IOPA X-rays) and mathematical calculation, proposed by Ingles and Messing, were used to observe and measure the length of individual root canal for tooth length. An endodontic access was prepared and pulp tissue was extirpated. A working length radiograph was taken with a file in the canal and the radiographic working length was established.
\end{abstract}

Results:This study revealed that the maximum, minimum and average tooth length of maxillary canine is $30 \mathrm{~mm}, 18 \mathrm{~mm}$ and $22.91 \mathrm{~mm}$ respectively.

Conclusion:The result indicates that the study previously performed by different researchers and those given in the different textbook of endodontics showed that the tooth length is shorter than the caucasoid counterpart.

Key Words:IOPA Xrays, Apex Locator, Root Canal Therapy, Tooth Length,

\section{Introduction:}

Root Canal Therapy is the treatment where there is the complete removable of the irreversibly damaged dental pulp followed by thorough cleaning, shaping and obturation of the root canal system so that the tooth may remain as a functional unit within the dental arch. Root Canal System anatomy plays a significant role in endodontic success and failure. These systems contain branches that communicate with the periodontal attachment apparatus furcally, laterally and often terminate apically into multiple portals of exits (1). However, even if $90 \%$ of all endodontic treatment is successful over time, the reciprocal failure rate is still $10 \%$. Improvement in the diagnosis and treatment of lesion of endodontic origin occurs with recognition of the interrelationships that exist between pulpal disease flow and egress of irritants along these anatomical pathways (2). Endodontic success and failure is related to the absence and presence of apical periodontitis (3). The etiologyof apical periodontitis isprimarily a bacterial infection of Root Canal System $(4,5)$ consequently the technical and pharmacological aspect of prevention and treatment are mainly aimed at controlling infection. Biomechanical and chemomechanical preparation of the root canal system varies in several respects (6).

Recent technological breakthroughs have been achieved in root canal procedures which have comparatively improved treatment results and feasibility of achieving success in the root canal therapy for patients with a range of $31 \%-100 \%$. The root canal system becomes a privileged sanctuary for microorganisms and pulpal tissue. The root canal therapy involves removing 
microorganisms from within the pulp space and the filling of the root canal system is done to prevent reinfection. The most challenging step in root canal therapy is determining working length. The accurate working length determination is a prerequisite for successful root canal therapy which reduces the chances of insufficient cleaning of the canal or damaging the periapical tissues from over instrumentation(7).

The ideal endpoint of endodontic instrumentation and obturation has been determined to be the cementodentinal junction. This anatomic landmark is called the minor diameter of the canal and represents the transition between pulpal and periodontal tissues, when instrumented and obturated to the minor diameter the contact between root canal filling material and the apical tissue is minimal. This is also the narrowest point in the canal and contains the smallest diameter of blood supply, thus creating the smallest wound site and the best condition for healing (8).

For the determination of the tooth length, root canal length has to be found out. The root canal length and apical foramen are still the tough task and the subject for several controversies but are basis for a successful Endodontic treatment. Radiographic interpretation still remains the best as every modern interpreter follows it $(9,10$ \& 11). Instruments shouldn't cross anatomic apex and should be confined in canal (12). The approximate tooth length is considered during diagnostic $\mathrm{x}$-ray. The knowledge of tooth length beforehand hence is beneficial. Tooth length determination is the crucial step in Endodontic treatment since instrumentation should be up to the optimal depth; any error in the steps follows failure of root canal treatment.

Radiographic working length is the standard measure for endodontic instrumentation in the dentinal portion of root canal. This measurement is difficult to achieve because the cementodentinal junction, the most apical portion of the dentinal canal, cannot be determined from a radiograph. Also, the cementodentinal junction can vary in relationship to major foramen. Variables in the radiographic technique, angulation, and exposure distort this image and lead to clinician error (13).

Although apex locators are a useful adjunct in locating the terminus of the root canal during endodontic therapy, they do not replace the need for radiograph. The ability of apex locators to accurately locate the apex varies from $55 \%$ - $95 \%(14,15)$. Studies also indicate that false readings are often obtained from electronic apex locators indicating the need for radiographic check films (16).

The tooth length of individual in the same race will be more or less same but varies in different races as the tooth length in Mongolians is not same as in Caucacian.The variation in root canal type creates many problems in root canal therapy among the canines, mandibular canine have greater length variation. Usually maxillary canine has less variation. In 1957, Ingles used the pretreatment radiograph in mathematical procedure for determining length. In modern dentistry most of the dental practitioner follows the method proposed by Ingles. Here we also calculated the tooth length in pretreatment radiograph as proposed by Ingles.

\section{Methods and Materials:}

The study was conducted at Nobel Medical College \& Teaching Hospital, Biratnagar, Nepal from January 2013 to December 2013. A total of 30 Endodontically treated maxillary canine were included in this study. Teeth with sound cusp anatomy and complete root apex on radiographs were selected.Teeth with broken/fractured crown, severely attrited teeth 
and patient under 16 years and over 55 years were excluded from the study. A detailed medical and dental history was taken. The selected patients were briefed about the procedure and the products. Their written consent was taken. Before starting any procedure a standardized periapical radiograph was taken for each tooth in buccolingual projection for finding the canal length and to exclude teeth with radiographically invisible canal, open apices, resorbed roots and root fracture. The radiolucent line of pulp canal on radiograph was studied with the help of magnifying glass. The purpose of magnifying glass was to enhance visualization of radiograph. After administration of local anaesthesia a conventional endodontic access was prepared. Pulp tissue was extirpated using barbed broaches. After pulp extirpation the canal was irrigated by copious amount of sodium hypochlorite solution. The absorbent paper points were used to dry the canal after irrigation of root canal. Then small numbered reamer/file (10/15) was selected, the selected reamer/file was introduced up to estimated length assuring that instrument did not cross the anatomical apex of the tooth. This is assured from preoperative radiograph, operator skill in tactile sensation, average tooth length proposed by various authors, clinician experience and digital apex locator $(4,5,6)$. The diagnostic radiograph was then taken.Calculation was then done. As proposed by Kuttler, re-diagnostic radiograph was taken when reamer/file was long or short by more than $1.5 \mathrm{~mm}$ from minor diameter (apical constriction). If it was within 1-1.5 $\mathrm{mm}$, interpolation was done. The selection of interpolation was within 0.5-1.5 mm.The favorable cusp was selected for coronal reference point and fixed by rubber stopper of reamer/file. After radiograph, the length was measured (RAL). Both reamer/file length and tooth length in radiograph was measured (XAL and XTL) respectively. As proposed by
Messing the mathematical calculation was done (Tooth Length $=$ RAL $x$ XTL / $\mathrm{XAL}$ ).Due to the reason of minor and major diameter as proposed by Kuttler, $0.5-2 \mathrm{~mm}$ is added according to the age of the patient.In this way the working length of the individual canal was calculated. Periapical radiograph was taken with careful inclination of the x-ray beam with the examined tooth.

\section{Fig: Steps in establishing accurate length of tooth measurement}

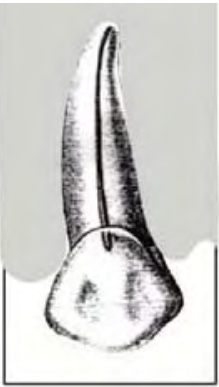

A

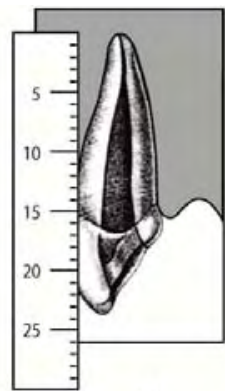

B

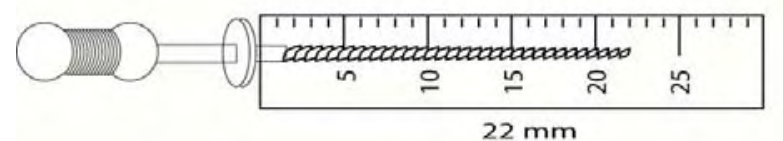

C
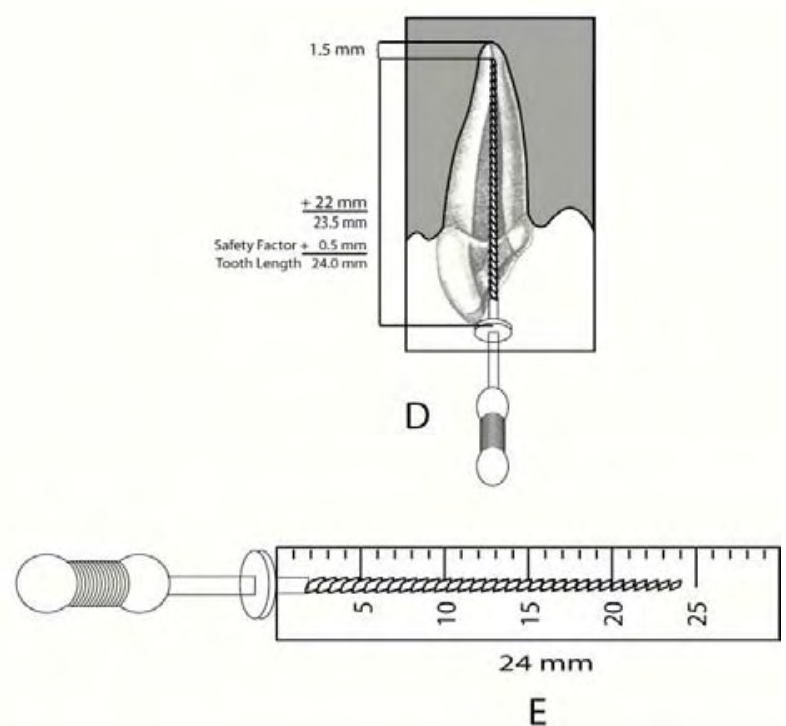

A. Maxillary canine. 
B. The length of the tooth is measured on diagnostic radiograph. Here the tooth appears to be $24 \mathrm{~mm}$ long from apex of tooth to the tip of cusp.

C. As safety precaution $2 \mathrm{~mm}$ is reduced from the initial length and then it is transferred to a diagnostic instrument.

D. The instrument is placed in the root canal and x-ray was taken. Then measurement is made from end of instrument to the end of root. Adding length of instrument in canal (here 22mm) to the length of instrument short of apex (here $1.5 \mathrm{~mm}$ ) will establish the accurate length of tooth (in this case $22+1.5 \mathrm{~mm})$.

E. Root canal and working length measurement: working length of the tooth is $23.5-0.5 \mathrm{~mm}=23 \mathrm{~mm}$; is set in an endodontic measuring gauge $0.5 \mathrm{~mm}$ is reduced as safety factor.

\section{Results:}

The maximum, average and minimum tooth length of maxillary canine is $30 \mathrm{~mm}, 22.91$ $\mathrm{mm}$ and $18 \mathrm{~mm}$ respectively, found in the maximum number of teeth (mode) as shown in (Table I);

Table I: Tooth length of $\mathbf{3 0}$ maxillary canine

\begin{tabular}{|l|l|l|}
\hline \multirow{4}{*}{$\begin{array}{l}\text { Maxillary } \\
\text { Canine }\end{array}$} & $\begin{array}{c}\text { Tooth Length } \\
(\mathbf{m m})\end{array}$ \\
\cline { 2 - 3 } & Average & 22.91 \\
\cline { 2 - 3 } & Maximum & 30.00 \\
\cline { 2 - 3 } & Minimum & 18.00 \\
\cline { 2 - 3 } & Mode & 24.00 \\
\cline { 2 - 3 } & $\begin{array}{l}\text { Standard } \\
\text { Deviation }\end{array}$ & $\mathbf{0 . 0 3 6}$ \\
\hline
\end{tabular}

The tooth length that was calculated in this study is compared with the length proposed by various researchers. (Table II)

Table II: Comparative study between the tooth length between various researchers

\begin{tabular}{|l|l|l|l|l|l|}
\hline & $\begin{array}{l}\text { NM } \\
\text { CTH }\end{array}$ & $\begin{array}{l}\text { Har } \\
\text { ty's }\end{array}$ & $\begin{array}{l}\text { Gross } \\
\text { man }\end{array}$ & $\begin{array}{l}\text { J. I. } \\
\text { Ingl } \\
\text { e’s }\end{array}$ & $\begin{array}{l}\text { F.S.W } \\
\text { eine }\end{array}$ \\
\hline $\begin{array}{l}\text { Maxil } \\
\text { lary } \\
\text { Cani } \\
\text { ne }\end{array}$ & $\begin{array}{l}22.91 \\
\text { mm }\end{array}$ & $\begin{array}{l}26.5 \\
\mathrm{~mm}\end{array}$ & $\begin{array}{l}\mathbf{2 6} \\
\mathrm{mm}\end{array}$ & $\begin{array}{l}\mathbf{2 6} \\
\mathrm{mm}\end{array}$ & $\begin{array}{l}\mathbf{2 7} \\
\mathrm{mm}\end{array}$ \\
\hline
\end{tabular}

\section{Discussion:}

With the advent of x-ray in dentistry by kells in 1899, it revolutionized the Endodontic dentistry and still use in routine to specialized works. Due to density of the tooth, it can be clearly viewed in $x$-ray and can assume the preoperative length (15). In 1900, it was proposed that cementodentinal junction is the ideal place to finish instrumentation and Endodontic obturation, since cementodentinal junction is the histological structure and not viewed by radiograph, it's difficult to find in x-ray. By the study of Palmar 50\% extend 1 $\mathrm{mm}$ or more through apical foramen when instrument is in radiographic apex and thereafter the instrumentation is limited to short of radiographic apex (1, 2, and 3).In 1955 Kuttler proposed the minor and major diameter. He stated that the instrumentation should be up to the major diameter, apical constriction, short of radiographic apex. Goldman \& co-worker found that interpretation of the dentist occur with $67 \%$ of cases. Nielson's study of radiograph interpretation showed that the examiners agreed on $65-75 \%$ of cases but the percentage increased when the same examiner reexamined the same radiograph. As Grossman stated that excellent radiograph might be difficult to read but poor radiograph is impossible to read. Angulations and distortion is greatly varied when many x-ray technician take the $\mathrm{x}$-ray (3).

Apex locator is another device that can detect the apex of tooth. However, there are number of controversies, as it depends upon its electric charges and ionic phage of medial in the canal (13). However, saline should not be 
used, as it is sensitive to apex locator (16). An apex locator can help in determining the working length during the root canal treatment, but it cannot replace periapical radiography. There is chance of missing the extra canal present in the tooth (17).

For this study, only one $\mathrm{x}$-ray technician took $\mathrm{x}$-rays, minimizing $\mathrm{x}$-ray angulations hazards and only one clinician interpreted the x-ray. To enhance visualization the clinician usually used magnifying glass thus minimizing radiographic misinterpretation. The instrument was used after diagnostic x-ray was taken but the statistic of the tooth where use of this device was not recorded. The x-ray technician tried to take every radiograph in parallel technique.

There are different methods proposed by various authors to calculate and determine the accurate working length of the tooth like "Estimation by Direct Digital Radiography or Xeroradiography, Digital Tactile Sense, Apical Periodontal Sensitivity" but the method used in NMCTH was by plain Radiographs (IOPA X-rays) followed by apex locator known as Ingle's method and this method showed high percentage of success with smaller variability. Since this method is cost effective, it is ideally used in most of the regions worldwide and has been proved to be the ideal method to determine the accurate working length of the particular tooth by the clinician of NMCTH.

Recently a modern device has been proposedEndometer ES-2. This was studied by Stare, Galic, Sutalo, Sagoric and Prshalo and was stated with $0.5-1 \mathrm{~mm}$ tolerance in precision of the Endometer ES-2 was $96.6 \%$ and within 2 mm tolerance it was $100 \%$.

\section{Conclusion:}

The length of the tooth also varies within the race. Though there is no specific study in this topic but the practitioners treating Negroid and Mongoloid are aware that the length found in textbooks, which are related to teeth of Caucasoid origin does not coincide with
Negroes and Mongolians.We have performed this study to determine the average tooth length and working length of tooth irrespective of sex as we didn't find any types of dependence between sex and tooth length. Thus, this length will help most of the clinicians in the treatment procedure and will reduce the failure of treatment.The maximum, minimum and average tooth length of maxillary canine is $30 \mathrm{~mm}, 18 \mathrm{~mm}$ and 22.91 $\mathrm{mm}$ respectively.

\section{References:}

1. Hess W, Zurcher E. The anatomy of the root Canals of the teeth of the permanent and deciduous dentition. New York: William wood \& CO; 1925: 45.

2. Schilder H. Canal debridement and disinfection. In: Cohen S, Burns RC, editors. Pathways of the pulp. $1^{\text {st }}$ ed. St. Louis: Mosby; 1976.

3. Stridberg LZ. The dependence of the result of pulp therapy on certain factors, an analytic study. Odontalgia Scandinivia 1956; 14: 99-101.

4. Hume WR. The pharmacological and toxicological properties of Zinc oxide-eugenol. JADA 1986; 113: 789-791.

5. Sundqvist G. Bacteriological studies of necrotic dental pulps. Thesis No. 7. Umea, Sweden: Umea University; 1976.

6. Stabholz A, Freidman S. Endodotic re-treatmentCase seletion and technique. Part 2: treatment planning for re-treatment. J Endod 1988; 14: 60714.

7. Iqbal Z, Memon RA. Comparision between radiographic and electronic working length determination in root canal treatment in vivo study. ISRA Medical Journal 2013; Volume 5, Issue 1; 41-46.

8. Ricucci D, Langeland K. Apical limit of root canal instrumentation and obturation, part 2. A histological study. Int Endod J 1998; 31:394-409.

9. John I. Ingle's - Endodontics. $5^{\text {th }}$ Edition. 2003.

10. Franklin S. Weine - Endodontic Therapy. St. Louis. C.V. Mosby Co.2004.

11. Louis. I. Grossman - Endodontic practices. $11^{\text {th }}$ Edition 1991.

12. Caldwell - Change in working length following instrumentation of molar canals Oral Surg. Jan. 1976. $41: 14$

13. Stein TJ, Corcoran JF. Radiographic "working length” evisited. Oral Surg Oral Med Oral Pathol 1992;

74:796-800. 
14. Fouad AF, Krell KV, McKendry DJ, Koorbusch GF, Olson RA. A clinical evaluation of five electronic root canal length measuring instruments. J Endod 1990; 16(1):446-9.

15. McDonald NJ, Hovland EJ. An evaluation of the apex locator endocater. J Endod 1990; 16:5-8.

16. Kim E, Marmo M, Lee CY, Oh NS, Kim IK. An in vivo comparison of working length determination by only Root-ZX apex locator versus combining Root-ZX apex locator with radiographs using a new impression technique. Oral Surg Oral Med Oral Med Pathol Oral Radiol Endod 2008Apr; 105(4):e79-83.

17. Peterson K, Lewis B. Endodontic status and suggested treatment in a population requiring substantial dental care. Endod Dent Traumatol 1989; 5:153-8.

Correspondence Address: Dr. Deependra NaulakhaAssistant Professor Department of Conservative Dentistry and Endodontics, Nobel Medical College \& Teaching Hospital, Kanchanbari, Biratnagar, Nepal. 